\title{
Simplified Mercury Extraction from Coal Fly Ash for Quantification of Total Mercury by ELISA-based Immunoassay
}

\author{
Yasumoto Date, ${ }^{* \dagger}$ Hiroyuki MaSAKI,* Arata AOTA,* Kazuhiro SASAKI,* Yukie NAMIKI,** \\ Thomas R. GLASS, $* * *$ and Naoya OHMURA* \\ *Environmental Science Research Laboratory, Central Research Institute of Electric Power Industry, 1646 Abiko, \\ Abiko, Chiba 270-1194, Japan \\ **Electric Power Engineering Systems Co., Ltd., 1646 Abiko, Abiko, Chiba 270-1194, Japan \\ ***Sapidyne Instruments Inc., 700 W. Diamond St, Boise, ID 83705, USA
}

\begin{abstract}
A simplified two-step mercury extraction procedure enabled the selective and reproducible mercury recovery from actual coal fly ash (CFA). The optimized extraction procedure involving conventional enzyme-linked immunosorbent assay (ELISA)-based immunoassay allowed the ultra-sensitive quantification of total mercury content in CFA. The total mercury content of 41 CFA samples were successfully determined using the above-mentioned method, and the results were in agreement with those obtained by standard instrumental analysis (thermal decomposition atomic absorption spectrometry) within a $15 \%$ coefficient of variation. Our method for total mercury quantification is not only simple but suitable for management of the mercury content at coal-fired electric power plants and landfill sites, which deal with large amounts of waste CFA.
\end{abstract}

Keywords Mercury, coal fly ash, immunoassay, simplified analysis, waste management

(Received September 9, 2019; Accepted December 2, 2019; Advance Publication Released Online by J-STAGE December 13, 2019)

\section{Introduction}

Coal-fired power plants, which account for $\sim 41 \%$ of global electricity production, ${ }^{1}$ discharge large quantities of coal combustion residues, such as coal fly ash (CFA). Current environmental regulations require the collection of this ash, which is commonly carried out using a dust collector such as an electric precipitator or a bug filter. The resulting coal fly ash that is not reused in the production of cement and concrete is disposed of safely in a designated landfill or impoundment site. Although the mercury present in CFA is relatively chemically stable,,$^{2,3}$ it can undergo methylation by environmental bacteria to produce highly neurotoxic organic mercury. ${ }^{4,5}$ Indeed, in river sediments close to large-scale coal ash spill sites, mercury methylation by sulfate-reducing bacteria has been suggested to take place through use of the sulfate ions present in the ash as a substrate. ${ }^{6,7}$ Furthermore, recent developments aimed at minimizing gaseous mercury emissions through the use of mercury controlling and capturing technologies, ${ }^{8}$ such as selective catalytic reduction, sorbent injection systems, and low temperature electronic precipitators, will likely lead to increased mercury content in the CFA.

Although frequent analysis is somewhat complicated and costly, evaluation of the mercury content in CFA and its distribution in waste disposal sites is essential to the management and risk assessment of the site. Conventionally, the total mercury content in environmental samples, such as CFA, have

$\dagger$ To whom correspondence should be addressed.

E-mail: date-ya@criepi.denken.or.jp been determined by techniques including thermal decomposition atomic absorption spectrometry (TD-AAS), ${ }^{9}$ cold vapor atomic absorption spectrometry (CV-AAS), ${ }^{10}$ atomic fluorescent spectroscopy, ${ }^{11}$ inductively coupled plasma mass spectrometry,,${ }^{12}$ or induced coupled plasma atomic emission spectrometry. ${ }^{13}$ Although these instrumental methods are accurate and sensitive, the development of simpler and more cost-effective techniques is required.

In this context, novel simplified detection principles have been actively studied, with examples including the use of nucleic acids such as DNAzyme and oligonucleotides, ${ }^{14-16}$ task-specific ionic liquids, ${ }^{17,18}$ and functionalized nanoparticles. ${ }^{19,20}$ However, these methods suffer from interference from other chemicals present in the fly ash samples. As such, the excellent specificity and relatively low cost of immunoassays ${ }^{21,22}$ render them an attractive alternative. Our group previously developed an antibody that is specific to chelated mercury ion, i.e., $\left(\mathrm{Hg}^{2+}\right)$ EDTA, ${ }^{23,24}$ and developed an immunoassay for trace mercury ion analysis in environmental water samples. ${ }^{23}$ However, although our antibody exhibited good specificity, the assay interference from coexisting metal ions was an issue since some of these ions are present in significantly greater concentrations than mercury itself.

To address this issue, rapid and inexpensive purification of mercury from a sample extract containing multiple other metal species is necessary using either a chelating resin or an ion exchange resin (IER). Although the lower cost and milder elution conditions offered by IERs make them better suited than chelating resins for mercury purification, ${ }^{23}$ their application to samples with high concentrations of other species, such as extracts of environmental solid samples, has not yet been 
examined in detail.

Thus, in this study, we developed a simplified two-step mercury-selective extraction method that can follow mercury using immunoassay to enable high-throughput and inexpensive quantitative determination of the mercury content in CFA. The proof of concept is demonstrated by a comparative analysis of 41 CFA samples from a coal-fired power plant; each of the samples was separately analyzed by TD-AAS, and mercury extraction was carried out by ELISA (enzyme-linked immunosorbent assay)-based quantitative determination for comparison.

\section{Experimental}

\section{Reagents and chemicals}

Two standard CFA samples, namely JSAC0521 (containing $140 \mu \mathrm{g} \mathrm{Hg} / \mathrm{kg}$ ) and JSAC0522 (mercury negative, $<10 \mu \mathrm{g} \mathrm{Hg} / \mathrm{kg}$ ), were purchased from The Japan Society for Analytical Chemistry (Japan). Actual CFA samples were collected from the electrostatic precipitator systems of full-scale pulverized coalfired power plants in Japan, which burn imported coal. The mercury standard solution $\left(\mathrm{HgCl}_{2}, 100 \mathrm{mg} / \mathrm{L}\right)$, potassium permanganate $\left(\mathrm{KMnO}_{4}, 99.5 \%\right)$, hydrochloric acid $(\mathrm{HCl}$, $99.5 \%)$, nitric acid $\left(\mathrm{HNO}_{3}, 99.5 \%\right)$, hydroxylamine hydrochloride $\left(\mathrm{HONH} \mathrm{HCl}_{3} \mathrm{HC}, 97 \%\right)$, and strongly basic anion exchange resin (DOWEX $1 \times 2,200$ - 400 mesh) were purchased from Wako Pure Chemical Industries, Ltd. (Japan). 5Sodium-2,2',2", $2^{\prime \prime \prime}$ (ethane-1,2-diyldinitrilo)tetraacetic acid (4Na-EDTA), and isothiocyanobenzyl-EDTA (ITCB-EDTA) were purchased from Dojindo Molecular Technologies, Inc. (Japan). Bovine serum albumin (BSA) was purchased from Sigma-Aldrich Japan K. K. (Japan), while the immunochemical blocking reagent N101 was purchased from NOF corporation (Japan). The anti- $\mathrm{Hg}^{2+}-\mathrm{EDTA}$ mouse monoclonal antibody (NX2C3) was prepared as described previously. ${ }^{24}$ The horseradish peroxidase (HLP) labelled antibody to mouse IgG(H+L) (KPL 074-1806), the colorimetric peroxidase substrate ABTS (KPL 50-62-00), and the peroxidase stop solution (KPL 50-85-01) were purchased from Kierkegaard \& Perry Laboratories, Inc., (MD, USA). All aqueous samples were prepared using distilled, deionized water obtained from an ultra-pure water production system (Direct8, Merck Millipore Japan). The phosphate buffered saline (PBS) was prepared in-house using solutions of $137 \mathrm{mM} \mathrm{NaCl}, 3 \mathrm{mM} \mathrm{KCl}, 20 \mathrm{mM}$ $\mathrm{Na}_{2} \mathrm{HPO}_{4}$, and $1.5 \mathrm{mM} \mathrm{KH}_{2} \mathrm{PO}_{4}$, and the $\mathrm{pH}$ was adjusted to 7.4 . PBSN was prepared by supplementing the PBS with $1 \%(\mathrm{w} / \mathrm{w})$ of the N101 blocking reagent.

\section{Ultrasound-assisted acid extraction}

Following a slight modification to our previously published extraction procedure, ${ }^{25}$ the sample of CFA $(0.5 \mathrm{~g})$ was dispersed in $0.5 \mathrm{M} \mathrm{HNO}_{3}(25 \mathrm{~mL})$ supplemented with $1 \mathrm{~g} / \mathrm{L} \mathrm{KMnO}_{4}$ in a $50 \mathrm{~mL}$ plastic bottle (I-boy, ASONE Inc., Japan). Following dispersal of the ash by vigorous shaking, the mixture was placed in the ultrasonic washing bath (USD-3R, ASONE, Japan) for $1 \mathrm{~h}$, and after this time, the resulting extract was filtered using a PTFE syringe filter (Dismic ${ }^{\circledR}-25 \mathrm{HP} 045 \mathrm{AN}$, Toyo Roshi Kaisha, Ltd, Japan). Hydroxylamine hydrochloride (HAC, $1 \mathrm{~g} / \mathrm{L}$ ) and $\mathrm{HCl}(1.0 \mathrm{M})$ were then added to the filtered solution before solid phase extraction depending on experiment conditions.

\section{Solid-phase extraction (SPE)}

The SPE column was prepared as described in a previous study. ${ }^{23}$ More specifically, the desired anion exchange resin (DOWEX $1 \times 2200-400$ ) was spread on a cellulose membrane
( $\phi 13 \mathrm{~mm}$ diameter) placed on the bottom of a $5-\mathrm{mL}$ plastic column (TERUMO, Japan) and covered with a second identical membrane. The columns were connected to the manifold (Supelco), and the suction pressure was set at $20 \mathrm{kPa}$ using an air pump. After flushing the column with the conditioning solution $(5 \mathrm{~mL}, 0.1 \mathrm{M} \mathrm{HCl})$, the sample extract solution $(5 \mathrm{~mL})$ was applied. To wash the coexisting metal adsorbed on the ion exchange resin, $0.1 \mathrm{M} \mathrm{HCl}(5 \mathrm{~mL})$ or $\mathrm{H}_{2} \mathrm{O}(5 \mathrm{~mL})$ or both were used. The adsorbed $\mathrm{Hg}^{2+}$ was eluted using $0.1 \mathrm{M}$ Tris- $\mathrm{HNO}_{3}$ buffer (10 mL; pH 7.5).

\section{Instrumental analysis}

The total mercury content in the CFA samples was accurately determined using TD-AAS with gold amalgamation (Nippon Instruments, Co., Ltd., Japan). The mercury ions present in the aqueous samples were determined using CV-AAS (Hg-20, Hiranuma Inc., Japan). The cadmium content of the aqueous samples was determined using ICP-MS (Agilent 7900, Agilent Technologies, Inc., CA, USA). The content of all other metal ions present in the aqueous samples was determined using ICPAES (Agilent 720-ES, Agilent Technologies, Inc., CA, USA). A calibration curve was employed for all instrumental determinations carried out herein.

\section{ELISA for mercury determination}

The antigen-protein conjugate (metal-EDTA-BSA) for ELISA was prepared (see Supporting Information) as described previously. ${ }^{26}$ In this study, $\mathrm{Cd}^{2+}$-EDTA, instead of $\mathrm{Hg}^{2+}$-EDTA, was employed as the quasi-antigen because of the instability of the latter in a protein-containing aqueous solution. The assay was carried out using a 96-well plate, where $\mathrm{Cd}^{2+}$-EDTA-BSA ( $50 \mu \mathrm{L} / \mathrm{well}, 2 \mu \mathrm{g} / \mathrm{mL})$ diluted with $50 \mathrm{mM}$ MES buffer (pH 6.5) was added to each well and incubated for $1 \mathrm{~d}$ at $4{ }^{\circ} \mathrm{C}$. After this time, the excess protein conjugate was removed by washing three times with PBSN $(200 \mu \mathrm{L} /$ well). An aliquot of the sample solution (standard mercury solution, or SPE eluate, $2 \mathrm{~mL})$ was mixed with the EDTA solution $(2 \mu \mathrm{L}, 20 \mathrm{mM})$ and after a few minutes, the anti- $\mathrm{Hg}^{2+}$-EDTA antibody was added $(20 \mu \mathrm{L}, 1 \mathrm{nM}$ final concentration), and the resulting mixture was incubated at $25^{\circ} \mathrm{C}$ for $15 \mathrm{~min}$. The antibody-containing measurement sample $(50 \mu \mathrm{L})$ was then added to the well, and incubation continued for $15 \mathrm{~min}$ at $25^{\circ} \mathrm{C}$. After washing four times with PBSN $(200 \mu \mathrm{L} /$ well), the HLP labelled antibody to mouse $\operatorname{IgG}(\mathrm{H}+\mathrm{L})(1.0 \mu \mathrm{g} / \mathrm{mL}$, KPL 074-1806) diluted with PBSN $(50 \mu \mathrm{L} /$ well) was added and incubation continued once more for $30 \mathrm{~min}$ at $25^{\circ} \mathrm{C}$. After this time, the excess secondary antibody was removed by washing five times with PBSN (200 $\mu \mathrm{L} /$ well). The colorimetric peroxidase substrate ABTS (100 $\mu \mathrm{L} /$ well, KPL 50-62-00) was then added and the mixture incubated for $15 \mathrm{~min}$ at $25^{\circ} \mathrm{C}$. To stop the coloration, the peroxidase stop solution ( $50 \mu \mathrm{L} /$ well, KPL 50-85-01) was added. Finally, optical measurements were carried out for each well using a multiwall plate reader (EL808, BIO-TEK instruments, Inc., VT). The results of the immunoassay were fitted using the four logistic functions as described in a previous report, using the least squares method. ${ }^{23}$

\section{Results and Discussion}

Solid-phase purification

Several coexisting metals were found in the extract of standard CFA samples (Table S1, Supporting Information). In particular, the levels of $\mathrm{Mn}, \mathrm{Al}$, and $\mathrm{Ca}$ in the JSAC0521 extract exceeded that of mercury by a factor of several thousands, and trace $\mathrm{Cd}$ 


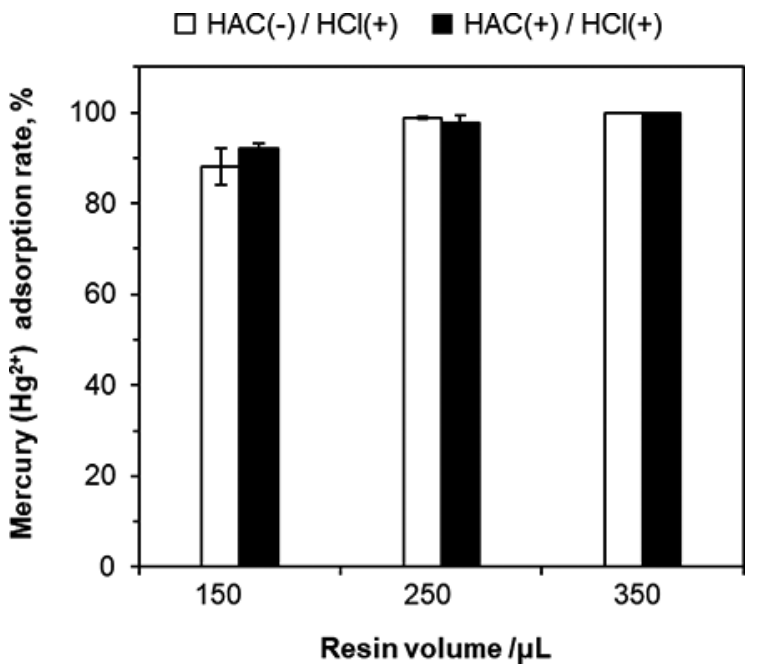

Fig. 1 Mercury adsorption by the anion exchange resin. The mockup extract in either the presence or absence of $\mathrm{HAC}$ and $\mathrm{HCl}$ was added to the resin-bedded column. Each column within the plot represents an average of three measurements along with the standard deviation.

(but highly reactive to antibody in use, Table S2, SI) was found in both extracts. To eliminate the above coexisting metals, extract purification was investigated.

Initially, the $\mathrm{Hg}^{2+}$ adsorption and elution conditions for the mockup extract were investigated. Thus, to evaluate the volume of IER required and the effects of supplementing the extract with $\mathrm{HCl}$ and $\mathrm{HAC}$ prior to passage through the column, the mock up extract $(5 \mathrm{~mL})$ containing $5 \mu \mathrm{g} / \mathrm{L} \mathrm{Hg}^{2+}\left(0.5 \mathrm{M} \mathrm{H}_{2} \mathrm{SO}_{4}\right.$ and $1 \mathrm{~g} / \mathrm{L} \mathrm{KMnO}_{4}$ ) supplemented or not supplemented with $\mathrm{HAC}(0.03 \mathrm{~g} / \mathrm{L}$ final concentration $)$ and $\mathrm{HCl}(0.1 \mathrm{M}$ final concentration) was applied to the SPE column packed with different volumes of the ion exchange resin (i.e., 150, 250, and $350 \mu \mathrm{L})$. Here, supplementation with $\mathrm{HCl}$ facilitated the formation of a $\mathrm{Hg}^{2+}$-chloride anionic complex that was adsorbed on the anion exchanging resin, ${ }^{23}$ while supplementation with $\mathrm{HAC}$ allowed one to scavenge $\mathrm{KMnO}_{4}$, which would otherwise damage the resin. Following collection of the eluate, the $\mathrm{Hg}^{2+}$ concentrations were measured, and as shown in Fig. 1, $>250 \mu \mathrm{L}$ of the ion exchange resin was required to achieve the optimal adsorption of $\mathrm{Hg}^{2+}(>95.5 \%)$ regardless of HAC supplementation.

This adsorbed $\mathrm{Hg}^{2+}$ from the mockup extract was then eluted using a $0.1 \mathrm{M}$ Tris- $\mathrm{HNO}_{3}$ buffer $(10 \mathrm{~mL}, \mathrm{pH} 7.5)$ and the various fractions collected. As shown in Fig. 2, the use of $4-5 \mathrm{~mL}$ of eluent resulted in the elution of $98.9-99.5 \%$ of the $\mathrm{Hg}^{2+}$ where $\mathrm{HAC}$ had been added to the applied sample, whereas $10 \mathrm{~mL}$ of eluent was required to elute $82.4 \%$ of the $\mathrm{Hg}^{2+}$ when $\mathrm{HAC}$ was absent from the system. The use of $\mathrm{HCl}$ and $\mathrm{HAC}$ supplementation of the extraction, in addition to $250 \mu \mathrm{L}$ IER resin and $5 \mathrm{~mL}$ eluent were therefore applied for the following experiments.

Subsequently, elimination of the coexisting metal species from the CFA extract was examined. Thus, residual metals present in the SPE column after the addition of the extracts $(5 \mathrm{~mL})$ prepared from the standard CFA samples (JSAC0521 and JSAC0522) were determined using the collected eluate, as outlined in Table 1. Although the elimination rates of coexisting metal ions were $77-100 \%$, non-negligible concentrations of $\mathrm{Mn}, \mathrm{Mg}, \mathrm{Fe}, \mathrm{Al}, \mathrm{Ca}$, and $\mathrm{Cd}$ were present following extract addition (see Table 1). In particular, the elimination of $\mathrm{Cd}$

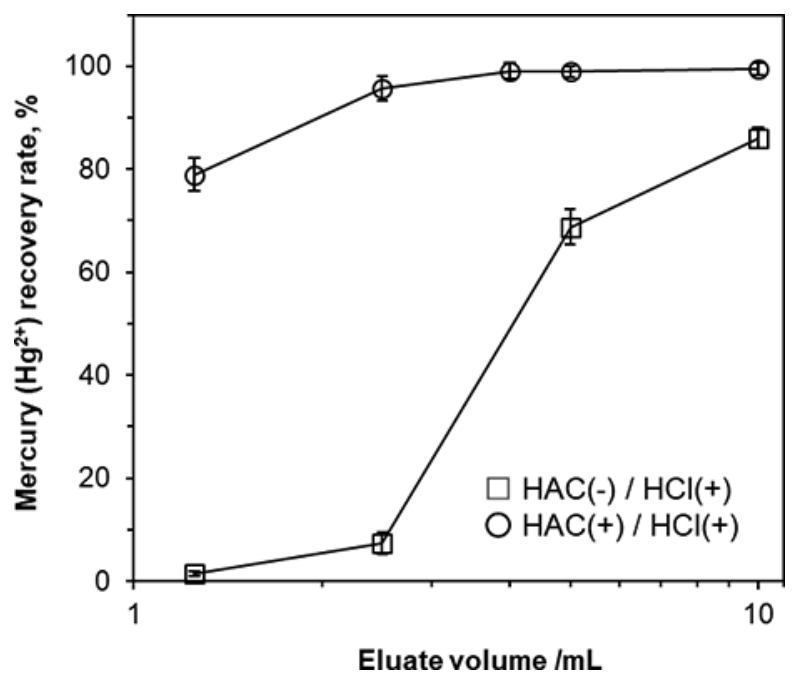

Fig. 2 Mercury elution from the anion exchange resin. The adsorbed mercury from the mockup extract was eluted using a neutral Tris$\mathrm{HNO}_{3}$ buffer. Each point represents an average of four measurements along with the standard deviation.

Table 1 Adsorption behavior of coexisting metals and anions

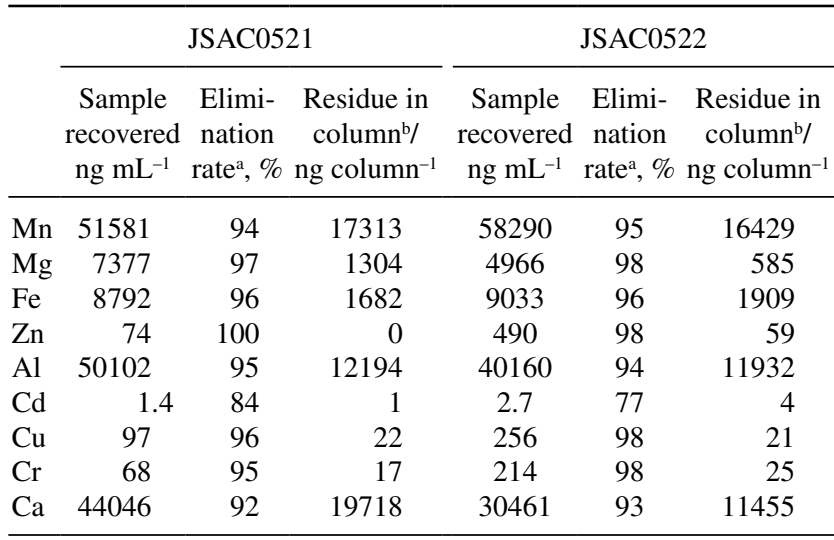

a. Elimination rate $(\%)$ was calculated from the concentrations of a given metal in the eluate and the sample (Table 1$)$ as $\left[100 \times\left(1-C_{\text {eluate }} /\right.\right.$ $\left.\left.C_{\text {sample }}\right)\right]$.

b. The residue in the column $(\mathrm{ng})$ was calculated as $\left[5(\mathrm{~mL}) \times\left(C_{\text {sample }}\right.\right.$ $\left.\left.-C_{\text {eluate }}\right)\right]$.

which exhibits a strong cross reaction to the antibody, is desirable. Thus, to eliminate any residual metal from the column, washing was carried out using pure water and/or $0.1 \mathrm{M}$ $\mathrm{HCl}$. More specifically, following application of the extract prepared from the standard CFA samples, $5 \mathrm{~mL}$ of either or both washing solutions were applied, and finally the Tris- $\mathrm{HNO}_{3}$ buffer $(5 \mathrm{~mL})$ was added to recover the $\mathrm{Hg}^{2+}$.

As presented in Fig. 3, several metal species, including $\mathrm{Cd}$, coexisted with the recovered $\mathrm{Hg}^{2+}(76.7 \%$ for JSAC0521, see Table 2) when washing was omitted. However, washing was found to result in the removal of residual metal species and elimination of the coexisting metals from the resulting elution buffer $(<10 \mu \mathrm{g} / \mathrm{mL})$, as shown in Fig. 3. In particular, washing with $\mathrm{HCl}$ and $\mathrm{H}_{2} \mathrm{O}$ gave superior results because of the efficient removal of coexisting metals $(\mathrm{Cd}, \mathrm{Mn}$ and $\mathrm{Al})$ to negligible levels in terms of cross reactivities of antibody in use ${ }^{23}$ (Table S2, with relatively high mercury recovery $(69.9 \%)$ ). Therefore, 

A $\square$ Without washing $\mathrm{H}_{2} \mathrm{O} \quad \mathrm{HCl}=\mathrm{HCl}-\mathrm{H}_{2} \mathrm{O}$

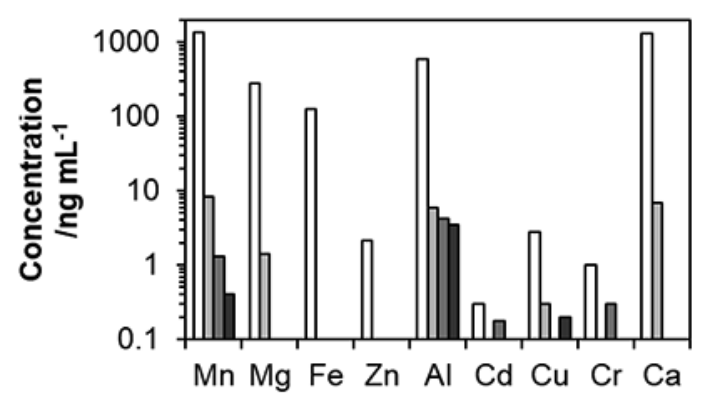

B

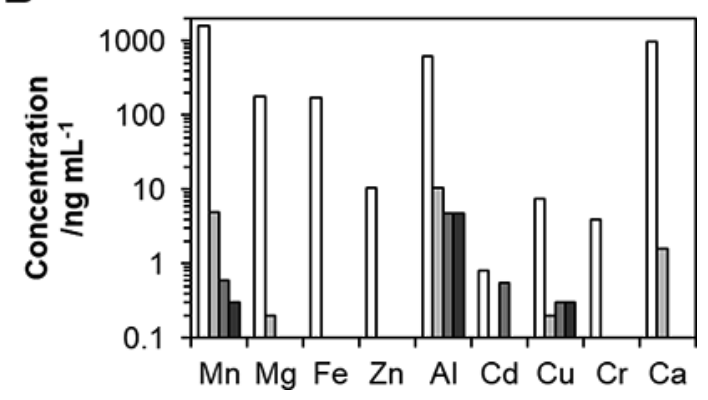

Fig. 3 Coexisting metals present in the conclusive eluate buffer both with and without washing in cases of (A) JSAC0521 and (B) JSAC0522.

Table 2 Mercury recovery through different washing procedures followed by elution

\begin{tabular}{lcc}
\hline Washing procedure & Recovery rate,$\%$ & CV, $\%$ \\
\hline None & $76.7 \pm 3.5$ & 4.5 \\
$\mathrm{H}_{2} \mathrm{O}$ & $41.0 \pm 3.9$ & 9.6 \\
$\mathrm{HCl}$ & $70.0 \pm 3.4$ & 4.9 \\
$\mathrm{HCl}-\mathrm{H}_{2} \mathrm{O}$ & $69.9 \pm 3.8$ & 5.4 \\
\hline
\end{tabular}

a. Recovery rate (\%) was calculated as $\left[\left(\mathrm{Hg}^{2+}\right.\right.$ concentration in eluate)/ $\left(\mathrm{Hg}^{2+}\right.$ concentration in sample $\left.) \times 100\right]$.

these conditions were employed for subsequent experiments.

Finally, the reproducibility of the mercury recovery was tested using the developed purification procedure through its application to actual samples (CFA1 - 7). Thus, the extracted solutions obtained from the CFA samples were mixed with $\mathrm{HAC}$ and $\mathrm{HCl}$ prior to loading onto the column, and after column washing with $\mathrm{HCl}-\mathrm{H}_{2} \mathrm{O}$, the adsorbed $\mathrm{Hg}^{2+}$ was recovered using the elution buffer. As outlined in Table 3, the recovery rate of mercury ranged from 63.3 to $79.6 \%$ (average $=$ $71.5 \%$ ) and corresponded well with the result obtained using the standard sample (JSAC0521).

\section{Actual sample analysis}

To demonstrate the quantitative utility of the described analytical procedure, 41 actual CFA samples were pretreated by optimized extraction and then measured by ELISA. For this purpose, calibration curves were first obtained using the CFA samples with known total mercury content through the use of TD-AAS (two standard CFA samples, 35, 139, 181, 232, and
Table 3 Mercury recovery by the optimized SPE method for samples with known mercury content

\begin{tabular}{lccr}
\hline $\begin{array}{c}\text { Sample } \\
\text { No. }\end{array}$ & $\begin{array}{c}\text { Mercury content }{ }^{\mathrm{a}} \\
\mu \mathrm{g} \mathrm{kg}^{-1}\end{array}$ & $\begin{array}{c}\text { Recovery rate } \\
\%\end{array}$ & $\begin{array}{c}\mathrm{CV}, \\
\%\end{array}$ \\
\hline JSAC0521 & 139 & $69.9 \pm 3.8$ & 5.4 \\
CFA1 & 35 & $79.6 \pm 8.0$ & 10.1 \\
CFA2 & 144 & $73.1 \pm 6.6$ & 9.0 \\
CFA3 & 153 & $63.3 \pm 1.2$ & 1.9 \\
CFA4 & 181 & $78.0 \pm 0.9$ & 1.2 \\
CFA5 & 176 & $68.5 \pm 1.3$ & 1.9 \\
CFA6 & 232 & $70.0 \pm 4.3$ & 6.1 \\
CFA7 & 957 & $67.7 \pm 0.9$ & 1.3 \\
\hline
\end{tabular}

a. Mercury content was measured by TD-AAS.

b. Recovery rate $(\%)$ was calculated as $\left[\left(\mathrm{Hg}^{2+}\right.\right.$ concentration in eluate $) /$ $\left(\mathrm{Hg}^{2+}\right.$ concentration in sample $\left.) \times 100\right]$.

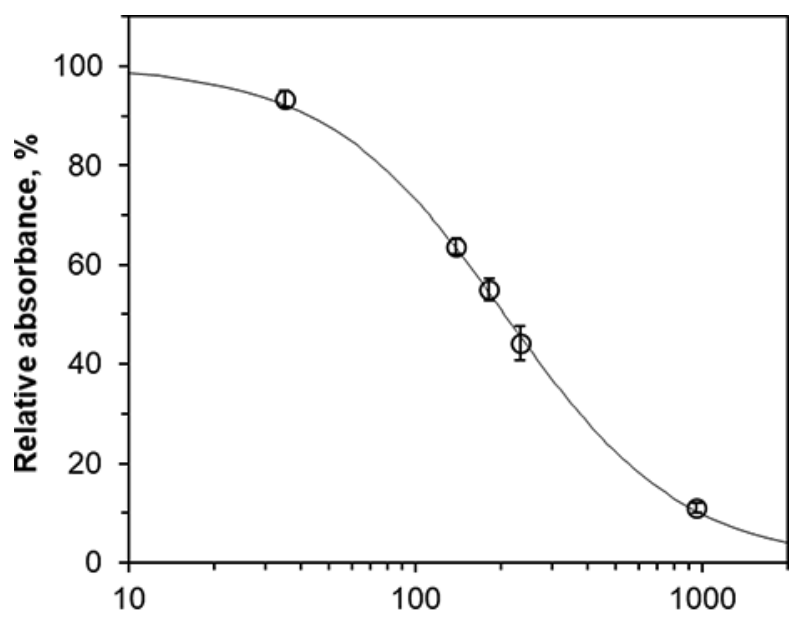

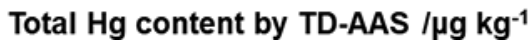

Fig. 4 Standard curve for total mercury determination. Each point represents an average of three measurements for samples of known concentrations along with the standard deviation.

$957 \mu \mathrm{g} / \mathrm{kg}$ ). Each immunoassay plot was fitted using the sigmoidal regression $(A=211, B=1.38)$, as shown in Fig. 4 . The detection limit of the total mercury content in the CFA samples calculated using the 3-sigma method was found to be $32.6 \mu \mathrm{g} / \mathrm{kg}$.

Forty-one actual CFA samples were extracted and purified using the optimized process described above and then analyzed using our developed immunoassay. As presented in Fig. 5, an excellent correlation was found between the determined values and the standard TD-AAS technique (slope $=1.03, R^{2}=0.98$ ). In addition, all data points presented a $<15 \%$ deviation from the ideal correlation (slope $=1$ ), which is sufficient for a quantitative method using immunoassay. ${ }^{27}$

\section{Conclusion}

We have reported the development of a simplified mercuryselective and reproducible extraction method to enable high throughput and inexpensive quantitative determination of mercury content in CFA using the conventional ELISA-based 


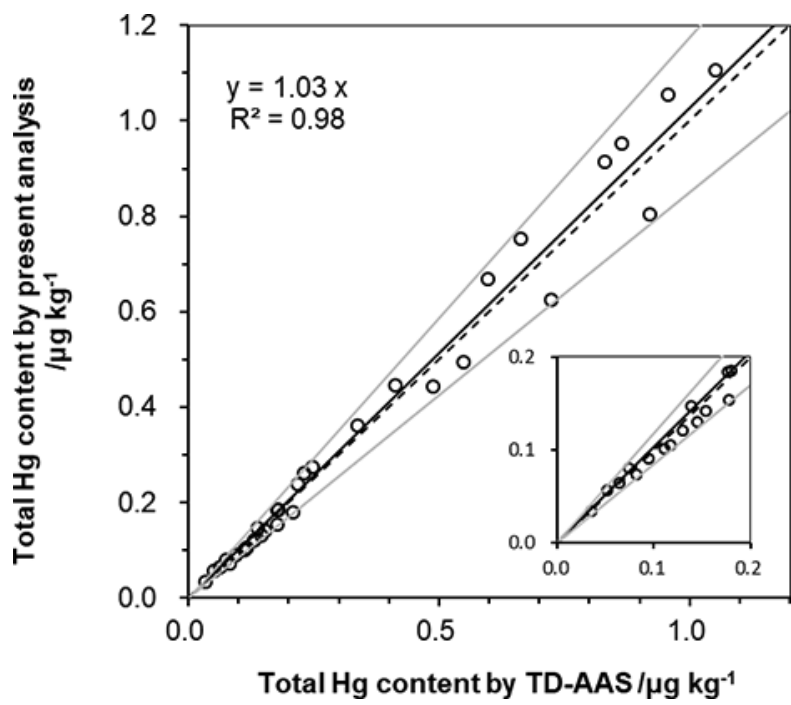

Fig. 5 Results of 41 actual CFA analysis. Each point represents the average of two measurements. The solid line indicates linear regression between the two data sets. The dotted line indicates the ideal correlation (slope $=1$ ). The gray solid lines indicate $\pm 15 \%$ deviation from the ideal correlation.

immunoassay. The low cost (US\$ 11.0/sample, see Table S3, SI) and simplicity of the complete process is believed to render it applicable for the monitoring of mercury in industrially produced CFA, which is a subject of worldwide concern. In the future, we will extend the analytical protocol developed herein to other solid wastes, such as sludge from waste water treatment at coal-fired power plants.

\section{Acknowledgements}

We would like to thank Editage (www.editage.com) for English language editing.

\section{Supporting Information}

Preparation of the antigen-protein conjugate. Contents of mercury and other metals in the standard CFA samples. Binding of NX2C3 antibody to mercury and other metals. Cost of present total $\mathrm{Hg}$ determination in CFA. This material is available free of charge on the Web at http://www.jsac.or.jp/analsci/.

\section{References}

1. IEA, "Tracking Clean Energy Progress 2017 Energy Technology Perspectives 2017 Excerpt Informing Energy Sector Transformations", 2017, International Energy Agency Publications.
2. M. Izquierdo and X. Querol, Int. J. of Coal Geo., 2012, 94, 54.

3. J. D. Noel, P. Biswas, and D. E. Giammar, J. Air Waste Manage Assoc., 2007, 57, 856.

4. R. R. Otter, D. McKinney, B. Brown, S. Lainer, W. Monroe, D. Hubbs, and B. Read, Environ. Monit. Assess., 2015, 187, 334.

5. J. L. Macalady, E. E. Mack, D. C. Nelson, and K. M. Scow, Appl. Environ. Microbiol., 2000, 66, 1479.

6. A. Deonarine, G. Bartov, T. M. Johnson, L. Ruhl, A. Vengosh, and H. Hsu-Kim, Environ. Sci. Technol., 2013, 47, 2100 .

7. G. Bartov, A. Deonarine, T. M. Johnson, L. Ruhl, A. Vengosh, and H. Hsu-Kim, Environ. Sci. Technol., 2013, 47, 2092.

8. E. J. Granite, H. W. Pennline, and C. Senior, "Mercury Control: For Coal-Derived Gas Streams", 2014, Wiley$\mathrm{VCH}$.

9. A. Ohki, K. Hayashi, J. Ohsako, T. Nakajima, and H. Takanashi, Microchem. J., 2013, 106, 357.

10. M. Horvat and V. Lupsina, Anal. Chim. Acta, 1991, $243,71$.

11. N. Bloom and W. F. Fitzgerald, Anal. Chim. Acta, 1988, 208, 151.

12. C. C. Wan, C. S. Chen, and S. J. Jiang, J. Anal. At. Spectrom., 1997, 12, 683.

13. S. Panyametheekul, Environ. Geochem. Health, 2004, 26, 51.

14. J. Wang and B. Liu, Chem. Commun., 2008, 4759.

15. J. Liu and Y. Lu, Angew. Chem., Int. Ed., 2007, 46, 7587.

16. M. Hollenstein, C. Hipolito, C. Lam, D. Dietrich and D. M. Perrin, Angew. Chem., Int. Ed., 2008, 47, 4346.

17. F. Loe-Mie, G. Marchand, J. Berthier, N. Sarrut, M. Pucheault, M. Blanchard-Desce, F. Vinet, and M. Vaultier, Angew. Chem., 2010, 49, 424.

18. A. Abu Ismaiel, M. K. Aroua, and R. Yusoff, Sensors (Basel), 2014, 14, 13102.

19. G. Sener, L. Uzun, and A. Denizli, Anal. Chem., 2014, 86, 514.

20. C. Y. Lin, C. J. Yu, Y. H. Lin, and W. L. Tseng, Anal. Chem., 2010, 82, 6830.

21. P. Chakrabarti, F. M. Hatcher, R. C. Blake, P. A. Ladd, and D. A. Blake, Anal. Biochem., 1994, 217, 70.

22. Y. Zhang, X. Li, G. Liu, Z. Wang, T. Kong, J. Tang, P. Zhang, W. Yang, D. Li, L. Liu, G. Xie, and J. Wang, Biol. Trace Elem. Res., 2011, 144, 854.

23. Y. Date, A. Aota, S. Terakado, K. Sasaki, N. Matsumoto, Y. Watanabe, T. Matsue, and N. Ohmura, Anal. Chem., 2013, 85, 434.

24. K. Sasaki, N. Yongvongsoontorn, K. Tawarada, Y. Ohnishi, T. Arakane, F. Kayama, K. Abe, S. Oguma, and N. Ohmura, J. Agric. Food Chem., 2009, 57, 4514.

25. H. Masaki, S. Inoba, S. Yasuike, and S. Ohyama, CRIEPI Report (in Japanese), 2009, Rep. No. V12002.

26. K. Sasaki, S. Oguma, Y. Namiki, and N. Ohmura, Anal. Chem., 2009, 81, 4005.

27. European Commission, "Laying Down Methods of Sampling and Analysis for the Official Control of Levels of Dioxins and Dioxin-like Pcbs in Certain Foodstuffs", 2006. 